\title{
Etiopathogenesis of Gastric Ulcer in Liver Cirrhosis
}

\author{
Ichiro Tsuruta \\ The Third Department of Internal Medicine, Kansai Medical University, \\ Moriguchi, Osaka 570, Japan \\ (Director : Prof. Yoshiko Sameshima) \\ (Received for Publication November 24, 1989) \\ Key words : Liver cirrhosis, Gastric ulcer, Gastric juice secretion, Gastric mucosa, \\ Arterio-venosclerosis
}

\section{Introduction}

Liver cirrhosis is frequently complicated by gastric ulceration and many studies have been published regarding the mechanism of this association. The major factors possibly responsible include the influence of hepatic dysfunction on the acid and pepsin contents of gastric juice, insufficient hepatic inactivation of gastric juice secretion stimulating factors, reduced resistance of the gastric mucosa due to malnutrition, disturbed gastric mucosal circulation due to elevated portal pressure, and interactions between gastrointestinal hormones. The exact mechanism is still unclear. In a previous paper, we reported on the high incidence of gastric ulcer in patients with liver cirrhosis ${ }^{1)}$. This time the relationship between liver cirrhosis and gastric ulceration was investigated by determining the kinetics of gastric juice secretion, the levels of gastrointestinal hormones, the condition of the gastric mucosa, the site of gastric ulceration, and the presence of esophageal varices. In addition, histopathological changes of gastric wall vessels, particularly arteriosclerosis and venosclerosis of the gastric wall, were investigated in autopsy cases.

\section{Clinical study}

\section{Subjects and Methods}

The subjects comprised 30 healthy controls, 49 patients with liver cirrhosis which included 27 with uncomplicated liver cirrhosis (LC) and 22 with liver cirrhosis plus gastric ulcer $(\mathrm{LC}+\mathrm{GU})$, and 29 patients with uncomplicated gastric ulcers (GU) (Table 1). For assessment of the kinetics of gastric juice secretion, the acid and pepsin levels in gastric juice were examined. Stimulation of gastric juice secretion was performed by the intramuscular injection of $4 \mu \mathrm{g} / \mathrm{kg}$ tetragastrin. Acid levels were determined according to the method proposed by the Gastric Juice Assay Committee of the Japanese Society of Gastroenterology ${ }^{2)}$. Pepsin activity was determined according to the protocol proposed by the same committee ${ }^{3)}$. Serum gastrin, secretin, and pepsinogen I levels were determined from blood samples taken immedia- 
Table 1. Subjects

\begin{tabular}{|c|c|c|c|c|c|c|c|}
\hline & \multicolumn{6}{|c|}{ Age (years) } & \multirow{3}{*}{ Total } \\
\hline & \multicolumn{2}{|c|}{$21-40$} & \multicolumn{2}{|c|}{$41-60$} & \multicolumn{2}{|c|}{$61-80$} & \\
\hline & Male & Female & Male & Female & Male & Female & \\
\hline Healthy controls & 5 & 4 & 7 & 5 & 4 & 5 & 30 \\
\hline $\begin{array}{l}\text { Liver cirrhosis } \\
\text { without gastric ulcer }\end{array}$ & 5 & 2 & 8 & 3 & 7 & 2 & 27 \\
\hline $\begin{array}{l}\text { Liver cirrhosis } \\
\text { with gastric ulcer }\end{array}$ & 4 & 2 & 8 & 2 & 5 & 1 & 22 \\
\hline Gastric ulcer & 5 & 3 & 6 & 4 & 7 & 4 & 29 \\
\hline
\end{tabular}

tely before the fasting gastric juice test was performed. Gastrin was determined by radioimmunoassay using Dainabot kit, secretin was determined using a Daiichi Radioisotope kit, and pepsinogen I was determined with a CIS kit. For examination of the gastric mucosa, dye endoscopy (Congo red test) was performed during stimulation by the intramuscular injection of tetragastrin ( $5 \mu \mathrm{g} / \mathrm{kg}$ body weight). In this examination, the glandular border which distinguishes the acid-secreting region (region of color change) from the non acid secreting region (region without color change) was classified according to the method of Miki et al. ${ }^{4)}$. Elevation of the border implies enlargement of the non acid secreting region, i.e., enlargement of the area of gastric mucosa affected by atrophic change. In addition, the mucosa of the antrum, the gastric angle, and the lower, middle and upper gastric bodies were biopsied at endoscopy to determine its background condition particularly the presence or absence of atrophic change. The degree of atrophic change of the mucosa was rated according to the 4-step scale (from normal to severe) of Iida et al. ${ }^{5)}$ Endoscopy was performed in order to observe the presence or absence of redness. To eliminate the influence of age, the site of ulceration was compared between respective age groups of the $\mathrm{LC}+\mathrm{GU}$ and GU groups. In addition, the presence or absence of esophageal varices and their severity were compared between the cirrhotic patients with and without gastric ulcers, using a proposed staging method $^{6}$.

\section{Pathological study}

The stomachs of the following patients were pathologically examined at autopsy : 47 cases in which liver cirrhosis was evident from autopsy findings, and 26 controls in which no histological changes of the liver were shown at autopsy (Table 2). In each case, 16 specimens of the stomach (from the lesser curvature, greater curvature, anterior and posterior walls of the antrum, middle and upper gastric bodies, and fornix) were prepared 
Table 2. Autopsied subjects

\begin{tabular}{|c|c|c|c|c|c|}
\hline & \multicolumn{4}{|c|}{ Age (years) } & \multirow{3}{*}{ Total } \\
\hline & \multicolumn{2}{|c|}{-60} & \multicolumn{2}{|c|}{$60-$} & \\
\hline & Male & Female & Male & Female & \\
\hline Controls & 6 & 5 & 8 & 7 & 26 \\
\hline $\begin{array}{l}\text { Liver cirrhosis } \\
\text { without gastric ulcer }\end{array}$ & 8 & 3 & 8 & 6 & 25 \\
\hline $\begin{array}{l}\text { Liver cirrhosis } \\
\text { with gastric ulcer }\end{array}$ & 7 & 2 & 9 & 4 & 22 \\
\hline
\end{tabular}

and stained with the Elastica van Gieson stain, Weigert's elastica, Azan-Mallory stain, periodic acid-Schiff-alcian blue stain, hematoxylin and eosin stain, and silver stain. Three arteries and veins in the submucosal layer were selected at random for assessment of vessel wall sclerosis according to the classifications of Kawamura et al. ${ }^{7)}$, (Table 3) and $\mathrm{Arai}^{8)}$, (Table 4), respectively. The degree of sclerosis was compared between patients above and below 60 years of age in each of the groups. Statistical significance of differences was evaluated using Student's t-test, and $\mathrm{P}<0.05$ was regarded as statistically significant.

Table 3. Classification of arteriosclerosis in the gastric wall
0 : No change
1: Thickening of the endothelium is seen around less than $1 / 10$ of the vessel.
2 : Thickening of the endothelium is seen around part of the vessel.
3 : Thickening of the endothelium is circumferential.
4 : The endothelium is partially the same thickness as the mesothelium.
5: The endothelium is the same thickness as the mesothelium.
6 : The endothelium is wider than the mesothelium.
7 : There is calcification or advanced stenosis of the lumen.

Table 4. Classification of venosclerosis in the gastric wall

0 : No change

1 : There is partial cellular intimal thickening.

2 : Cellular intimal thickening is circumferential.

3 : There is partial cellular/fibrous intimal thickening.

4: Cellular/fibrous intimal thickening is circumferential.

5: There is partial fibrous intimal thickening.

6 : Fibrous intimal thickening is circumferential.

7 : The wall is thinned due to variceal distension in addition to the above. 


\section{Results}

\section{Clinical study}

\section{1. Kinetics of gastric juice secretion}

Basal acid output (BAO) (Fig. 1)

The BAO was $1.87 \pm 0.95 \mathrm{mEq} / \mathrm{hr}$ in healthy controls, $0.80 \pm 0.35 \mathrm{mEq} / \mathrm{hr}$ in LC group, $1.06 \pm 0.73 \mathrm{mEq} / \mathrm{hr}$ in $\mathrm{LC}+\mathrm{GU}$ group, and $1.74 \pm 0.95 \mathrm{mEq} / \mathrm{hr}$ in GU group. Thus, the $\mathrm{BAO}$ values in $\mathrm{LC}$ and $\mathrm{LC}+\mathrm{GU}$ groups were significantly lower than in GU group and healthy controls $(P<0.01)$. The $\mathrm{BAO}$ in $\mathrm{LC}+\mathrm{GU}$ group was not significantly higher than in LC group.

\section{Maximal acid output (MAO) (Fig. 1)}

The MAO was $10.26 \pm 2.35 \mathrm{mEq} / \mathrm{hr}$ in healthy controls, $6.26 \pm 3.14 \mathrm{mEq} / \mathrm{hr}$ in $\mathrm{LC}$ group, $8.16 \pm 3.43 \mathrm{mEq} / \mathrm{hr}$ in $\mathrm{LC}+\mathrm{GU}$ group, and $8.97 \pm 3.27 \mathrm{mEq} / \mathrm{hr}$ in GU group. Thus, the MAO in LC group was significantly lower than in healthy controls and GU group $(\mathrm{P}<0.01)$, and the MAO in $\mathrm{LC}+\mathrm{GU}$ group was significantly lower than in healthy controls $(\mathrm{P}<0.01)$. The MAO in $\mathrm{LC}+\mathrm{GU}$ group was not significantly higher than in LC group.

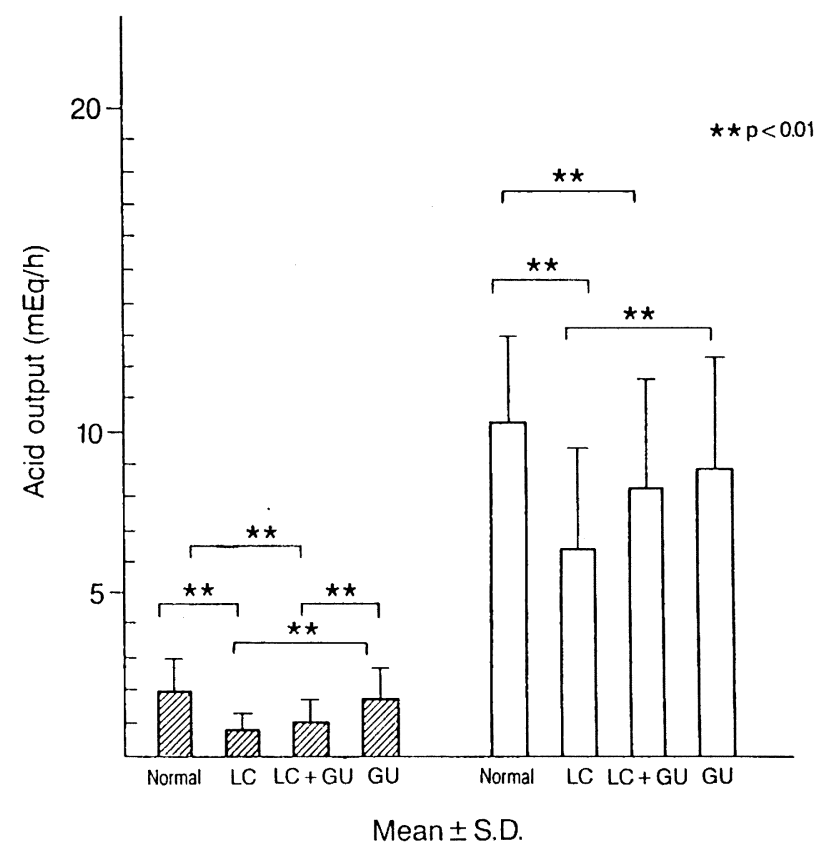

Fig. 1. Gastric acid output

Normal, Healthy controls ; LC, Liver cirrhosis without gastric ulcer ;

$\mathrm{LC}+\mathrm{GU}$, Liver cirrhosis with gastric ulcer; GU, Gastric ulcer

Basal acid output ( BAO), Maximal acid output ( $\square$ MAO) 


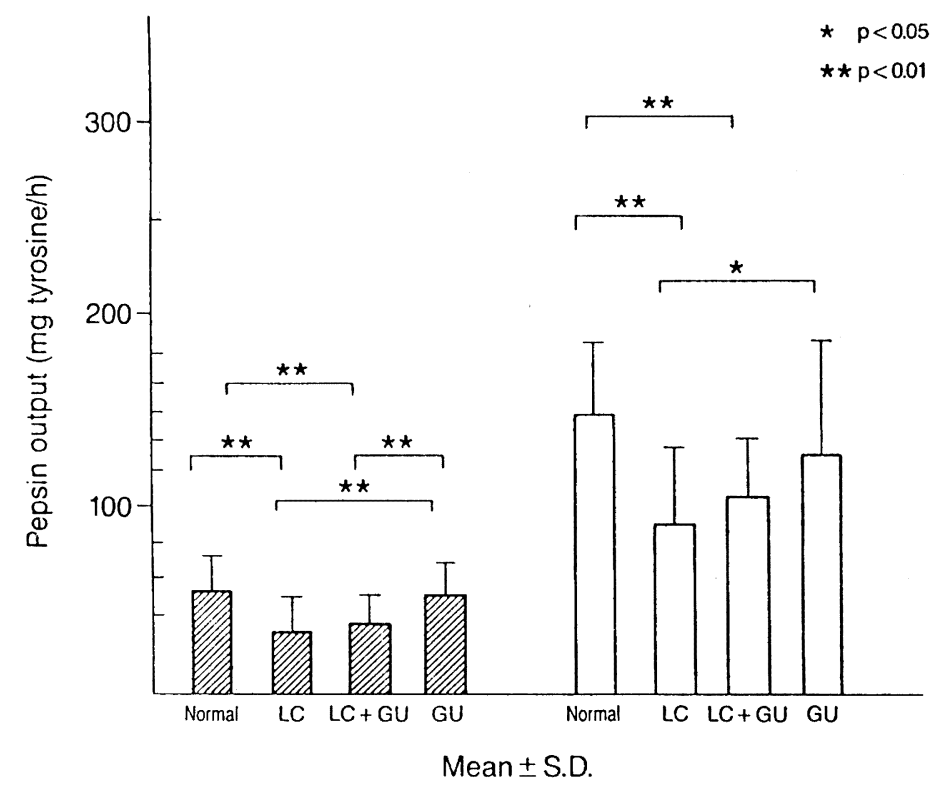

Fig. 2. Pepsin output

Normal, Healthy controls ; LC, Liver cirrhosis without gastric ulcer ;

LC+GU, Liver cirrhosis with gastric ulcer ; GU, Gastric ulcer

Basal pepsin output (BPO), Stimulated pepsin output ( $\square$ SPO).

Basal pepsin output (BPO) (Fig. 2)

The BPO was $55.73 \pm 15.72 \mathrm{mg}$ of tyrosine/hr in healthy controls, $30.72 \pm 12.32 \mathrm{mg}$ of tyrosine $/ \mathrm{hr}$ in LC, $34.77 \pm 14.76 \mathrm{mg}$ of tyrosine $/ \mathrm{hr}$ in $\mathrm{LC}+\mathrm{GU}$, and $49.27 \pm 23.01 \mathrm{mg}$ of tyrosine/hr in GU. The BPO values in LC and LC+GU groups were significantly lower than in healthy controls and GU group $(\mathrm{P}<0.01)$. The BPO in $\mathrm{LC}+\mathrm{GU}$ group was not significantly higher than in LC group.

Stimulated pepsin output (SPO) (Fig. 2)

The SPO was $146.70 \pm 41.53 \mathrm{mg}$ of tyrosine/hr in healthy controls, $88.18 \pm 39.16 \mathrm{mg}$ of tyrosine $/ \mathrm{hr}$ in $\mathrm{LC}, 105.60 \pm 33.51 \mathrm{mg}$ of tyrosine/hr in $\mathrm{LC}+\mathrm{GU}$, and $129.84 \pm 55.98 \mathrm{mg}$ of tyrosine/hr in GU. The SPO values in LC and LC+GU groups were significantly lower than those in healthy controls $(\mathrm{P}<0.01)$, and SPO in $\mathrm{LC}+\mathrm{GU}$ group was significantly lower than in GU group $(P<0.05)$. The $\mathrm{SPO}$ in $\mathrm{LC}+\mathrm{GU}$ group was not significantly higher than in LC group.

\section{2. Gastrointestinal hormones}

Fasting serum gastrin (FSG) (Fig. 3)

The FSG level was $93.17 \pm 21.73 \mathrm{pg} / \mathrm{ml}$ in healthy controls, $83.23 \pm 42.27 \mathrm{pg} / \mathrm{ml}$ in LC 
$S-68$

group, $99.70 \pm 30.71 \mathrm{pg} / \mathrm{ml}$ in $\mathrm{LC}+\mathrm{GU}$ group, and $90.28 \pm 39.23 \mathrm{pg} / \mathrm{ml}$ in GU group. No significant difference was observed between $\mathrm{LC}$ and $\mathrm{LC}+\mathrm{GU}$ groups.

Fasting serum secretin (FSS) (Fig. 3)

The FSS level was $107.17 \pm 20.94 \mathrm{pg} / \mathrm{ml}$ in healthy controls, $123.04 \pm 27.90 \mathrm{pg} / \mathrm{ml}$ in $\mathrm{LC}$, $114.98 \pm 23.21 \mathrm{pg} / \mathrm{ml}$ in $\mathrm{LC}+\mathrm{GU}$, and $121.41 \pm 45.77 \mathrm{pg} / \mathrm{ml}$ in $\mathrm{GU}$. No significant difference was observed between LC and LC+GU groups.

\section{3. Fasting serum pepsinogen $I$}

Fasting serum pepsinogen I (PGI) (Fig. 3)

The PGI level was $80.68 \pm 25.03 \mathrm{ng} / \mathrm{ml}$ in healthy controls, $63.36 \pm 25.48 \mathrm{ng} / \mathrm{ml}$ in LC, $67.74 \pm 14.22 \mathrm{ng} / \mathrm{ml}$ in $\mathrm{LC} \pm \mathrm{GU}$, and $79.83 \pm 22.45 \mathrm{ng} / \mathrm{ml}$ in GU. The PGI levels in LC and $\mathrm{LC}+\mathrm{GU}$ groups were significantly lower than in healthy controls and GU group $(\mathrm{P}<0.05)$, although this parameter did not significantly differ between LC and LC + GU groups.

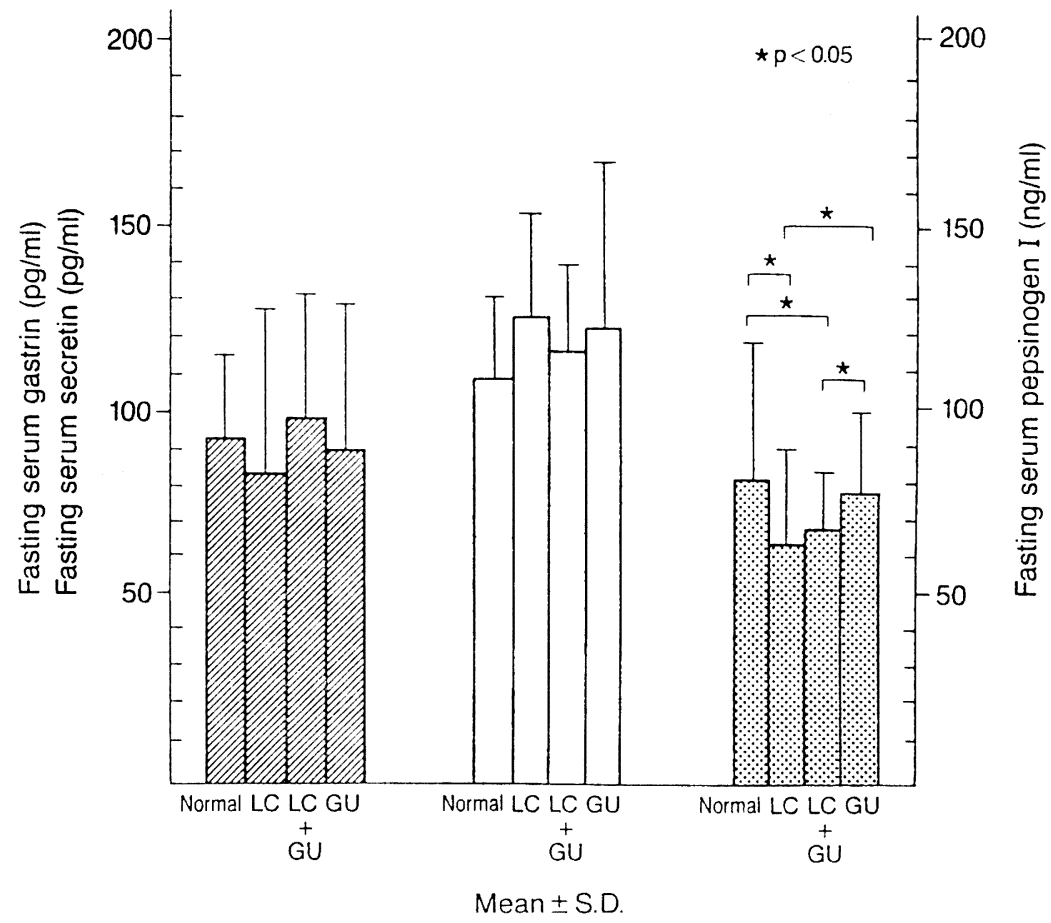

Fig. 3. Fasting serum gastrin ( 睴 FSG), fasting serum secretin

( $\square$ FSS) and fasting serum pepsinogen I ( $\square$ PGI) levels.

Normal, Healthy controls ; LC, Liver cirrhosis without gastric ulcer ; $\mathrm{LC}+\mathrm{GU}$, Liver cirrhosis with gastric ulcer ; GU, Gastric ulcer. 


\section{4. Gastric mucosa}

Glandular border examination by the Congo red test (Table 5)

The glandular border was classified into the closed type $\left(\mathrm{C}_{0}-\mathrm{C}_{2}\right)$ and the open type $\left(\mathrm{O}_{1}\right.$ $-\mathrm{O}_{3}$ ). The level of the glandular border in $\mathrm{LC}$ and $\mathrm{LC}+\mathrm{GU}$ groups tended to be higher than in healthy controls and GU group at all ages.

Endoscopic appearance of the mucosa (Table 6)

Table 5. Appearance of the glandular border in the endoscopic congo red test

\begin{tabular}{|c|c|c|c|c|c|c|c|c|c|c|c|c|c|c|c|c|c|c|}
\hline & \multicolumn{18}{|c|}{ Age (years) } \\
\hline & \multicolumn{6}{|c|}{$21-40$} & \multicolumn{6}{|c|}{$41-60$} & \multicolumn{6}{|c|}{$61-80$} \\
\hline & \multicolumn{3}{|c|}{ Closed type } & \multicolumn{3}{|c|}{ Open type } & \multicolumn{3}{|c|}{ Closed type } & \multicolumn{3}{|c|}{ Open type } & \multicolumn{3}{|c|}{ Closed type } & \multicolumn{3}{|c|}{ Open typ } \\
\hline & $\mathrm{C}_{0}$ & $\mathrm{C}_{1}$ & $\mathrm{C}_{2}$ & 0 & & $\mathrm{O}_{3}$ & $\mathrm{C}_{0}$ & ${ }_{0} \mathrm{C}_{1}$ & $\mathrm{C}_{2}$ & $\mathrm{O}_{1}$ & & $\mathrm{O}_{3}$ & & $\mathrm{C}_{1}$ & $\mathrm{C}_{2}$ & & $\mathrm{O}_{2}$ & $\mathrm{O}_{3}$ \\
\hline Healthy controls & 4 & 3 & 1 & 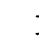 & 0 & 0 & 1 & 5 & 2 & 2 & 2 & 0 & 1 & 2 & 2 & 2 & 1 & 1 \\
\hline $\begin{array}{l}\text { Liver cirrhosis } \\
\text { without gastric ulcer }\end{array}$ & 1 & 2 & 2 & 1 & 1 & 0 & 2 & 1 & 3 & 3 & 2 & 1 & 1 & 1 & 1 & 3 & 2 & 1 \\
\hline $\begin{array}{l}\text { Liver cirhosis } \\
\text { with gastric ulcer }\end{array}$ & 1 & 1 & 1 & 2 & 1 & 0 & 1 & 2 & 2 & 2 & 2 & 1 & 0 & 1 & 1 & 1 & 2 & 1 \\
\hline Gastric ulcer & 2 & 3 & 2 & i & 0 & 0 & 2 & 4 & 1 & 1 & 1 & 1 & 2 & 2 & 2 & 3 & 1 & 1 \\
\hline
\end{tabular}

Table 6. Gastric mucosal atrophy and erythema in the four groups

\begin{tabular}{|c|c|c|c|c|c|c|c|c|}
\hline & \multirow{2}{*}{$\underset{\text { (years) }}{\text { Age }}$} & \multirow{2}{*}{$\begin{array}{l}\text { No. of } \\
\text { patients }\end{array}$} & \multicolumn{4}{|c|}{ Atrophic change } & \multicolumn{2}{|c|}{ Erythema } \\
\hline & & & $(-)$ & $(+)$ & (H) & (冊) & $(-)$ & $(+)$ \\
\hline \multirow{3}{*}{ Healthy controls } & $21-40$ & 9 & 6 & 3 & & & 8 & 1 \\
\hline & $41-60$ & 12 & 6 & 5 & 1 & & 11 & 1 \\
\hline & $61-80$ & 9 & 3 & 4 & 2 & & 7 & 2 \\
\hline \multirow{3}{*}{$\begin{array}{l}\text { Liver cirrhosis } \\
\text { without gastric ulcer }\end{array}$} & $21-40$ & 7 & 3 & 3 & & 1 & 4 & 3 \\
\hline & $41-60$ & 11 & 2 & 4 & 3 & 2 & 5 & 6 \\
\hline & $61-80$ & 9 & 1 & 3 & 4 & 1 & 3 & 6 \\
\hline \multirow{3}{*}{$\begin{array}{l}\text { Liver cirrhosis } \\
\text { with gastric ulcer }\end{array}$} & $21-40$ & 6 & 1 & 2 & 2 & 1 & 2 & 4 \\
\hline & $41-60$ & 10 & 1 & 3 & 4 & 2 & 4 & 6 \\
\hline & $61-80$ & 6 & 1 & 2 & 1 & 2 & 1 & 5 \\
\hline \multirow{3}{*}{ Gastric ulcer } & $21-40$ & 8 & 4 & 3 & 1 & & 6 & 2 \\
\hline & $41-60$ & 10 & 4 & 3 & 2 & 1 & 8 & 2 \\
\hline & $61-80$ & 11 & 3 & 5 & 2 & 1 & 8 & 3 \\
\hline
\end{tabular}


Atrophic change and redness tended to be more frequent in $\mathrm{LC}$ and $\mathrm{LC}+\mathrm{GU}$ groups than in healthy controls and GU group.

Site of ulceration

As shown in Fig. 4, GU and LC+GU groups frequently had ulcers in the gastric angle and lesser curvature at all ages.
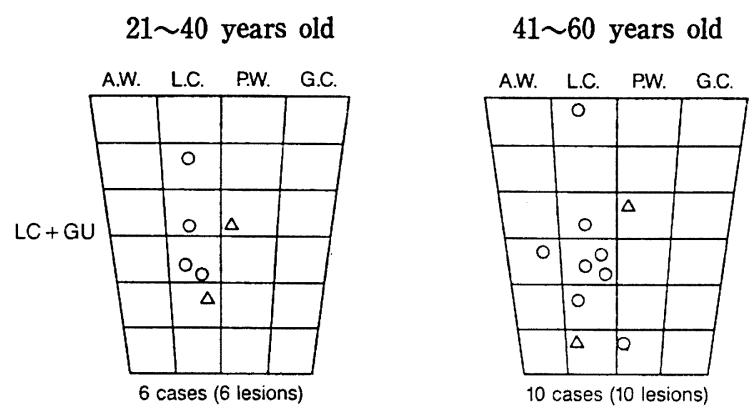

$91 \sim 80$ years old
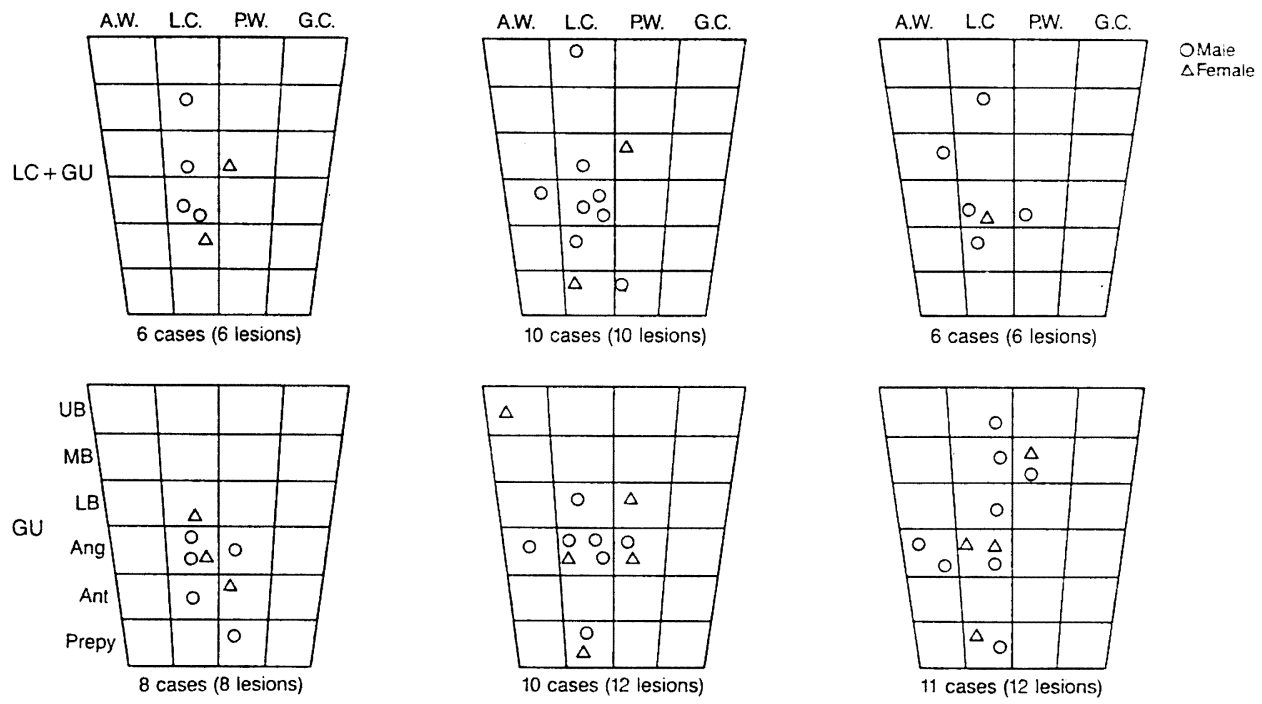

Fig. 4. Locations of gastric ulcers in patients with liver cirrhosis with gastric ulcer and gastric ulcer alone by age and sex.

A.W., anterior wall ; L.C., lesser curvature ; P.W., posterior wall ;

G.C. greater curvature ; U. B. upper body ; M. B., middle body ; L. B., lower body ; Ang, angle ; Ant, antrum ; Prepy, prepylorus.

Table 7. Clinical stage of esophageal varices in liver cirrhotic patients with and without gastric ulcer

\begin{tabular}{|c|c|c|c|c|c|c|c|c|c|c|c|c|c|c|}
\hline \multirow{3}{*}{ Group } & \multirow{3}{*}{$\begin{array}{l}\text { No. of } \\
\text { patients } \\
\text { with } \\
\text { varices }\end{array}$} & \multicolumn{13}{|c|}{ Stage } \\
\hline & & & \multicolumn{3}{|c|}{ I } & \multicolumn{3}{|c|}{ II } & \multicolumn{3}{|c|}{ III } & \multicolumn{3}{|c|}{ IV } \\
\hline & & $\underset{\text { (years) }}{\text { Age }}$ & $\begin{array}{c}21 \\
1 \\
40\end{array}$ & $\begin{array}{c}41 \\
\mid \\
60\end{array}$ & $\begin{array}{c}61 \\
1 \\
80\end{array}$ & $\begin{array}{c}21 \\
\mid \\
40\end{array}$ & $\stackrel{1}{1}_{60}^{41}$ & $\begin{array}{l}61 \\
1 \\
80\end{array}$ & ${ }_{40}^{21}$ & $\begin{array}{c}41 \\
1 \\
60\end{array}$ & $\begin{array}{c}61 \\
\mid \\
80\end{array}$ & $\begin{array}{c}21 \\
1 \\
40\end{array}$ & $\begin{array}{c}41 \\
\mid \\
60\end{array}$ & $\begin{array}{c}61 \\
1 \\
80\end{array}$ \\
\hline $\begin{array}{l}\text { Liver cirrhosis } \\
\text { without gastric ulcer }\end{array}$ & 11 & & 1 & 3 & 2 & 0 & 1 & 2 & 0 & 1 & 1 & 0 & 0 & 0 \\
\hline $\begin{array}{l}\text { Liver cirrhosis } \\
\text { with gastric ulcer }\end{array}$ & 14 & & 1 & 3 & 1 & 1 & 2 & 2 & 1 & 2 & 1 & 0 & 0 & 0 \\
\hline
\end{tabular}




\section{5. Esophageal varices in the liver cirrhosis without gastric ulcer and liver cirrhosis} with gastric ulcer.

As shown in Table 7, the presence of esophageal varices was more frequent in $\mathrm{LC}+\mathrm{GU}$ group than in LC group. In $\mathrm{LC}+\mathrm{GU}$ patients with esophageal varices, the varices were often severe i.e., Stage III where the red color sign is visible.

\section{Pathological study}

\section{1. Arteriosclerosis}

As shown in Fig. 5, the arteriosclerotic index (A. I.) of the antrum in patients aged over 60 was significantly lower in cirrhotic patients with gastric ulcer $(1.38 \pm 0.62)$ and without gastric ulcer $(0.99 \pm 0.60)$ than those of controls $(2.36 \pm 0.67)(P<0.01)$. The A.I. of the

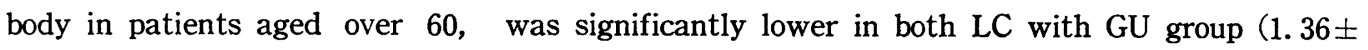
$0.61)$ and LC without GU group (1.21 \pm 0.51$)$ than those of Control group (2.74 \pm 0.72$)$ $(\mathrm{P}<0.01)$. In the fornix aged over 60, the index was significantly lower in both $\mathrm{LC}+\mathrm{GU}$

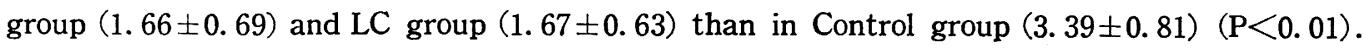

In controls aged over 60 , the A.I. was significantly lower in the antrum $(2.36 \pm 0.67)$ than in the fornix $(3.39 \pm 0.81)(P<0.01)$, as shown in Fig. 5. In uncomplicated cirrhotic patients aged over 60 , the index in the antrum $(0.99 \pm 0.60)$ was also significantly lower than that in the fornix $(1.67 \pm 0.63)(\mathrm{P}<0.05)$.

\section{2. Venosclerosis}

As shown in Fig. 6, in the antrum of patients aged under 60, the venosclerotic index (V.I.) was significantly higher in both cirrhotic patients with $(4.38 \pm 0.66)$ and without gastric ulcer $(4.26 \pm 0.75)$ than in controls $(1.60 \pm 0.66)(\mathrm{P}<0.001)$. In the body of patients

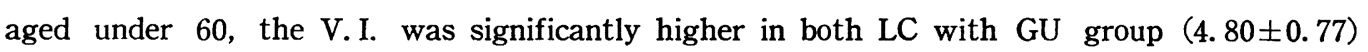

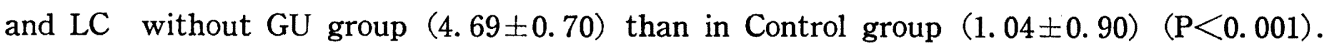

In the fornix of patients aged under 60 , the index was significantly higher in both LC with GU group (5.39 \pm 0.78$)$ and LC without GU group (5.12 \pm 0.91$)$ than in Control group $(1.98 \pm 0.93)(P<0.001)$. In the antrum of patients aged over 60 , the V.I. was significantly higher in both cirrhotic patients with gastric ulcer (4.24 \pm 0.78$)$ and without gastric ulcer $(4.21 \pm 0.66)$ than in controls $(1.86 \pm 0.80)(\mathrm{P}<0.001)$. In the body of patients aged over 60 , the V.I. was significantly higher in both LC with GU group (4.64 \pm 0.73$)$ and LC without GU group $(4.36 \pm 1.01)$ than in Control group $(1.71 \pm 0.74)(\mathrm{P}<0.001)$. In the fornix of patients aged over 60 , the index was significantly higer in both LC with GU group $(5.01 \pm 0.91)$ and LC without GU group $(4.77 \pm 0.90)$ than in Control group (2.07 \pm 0.98$)$ $(\mathrm{P}<0.001)$.

As shown in Fig. 6, in cirrhotic patients with gastric ulcer aged under 60, the V.I. 

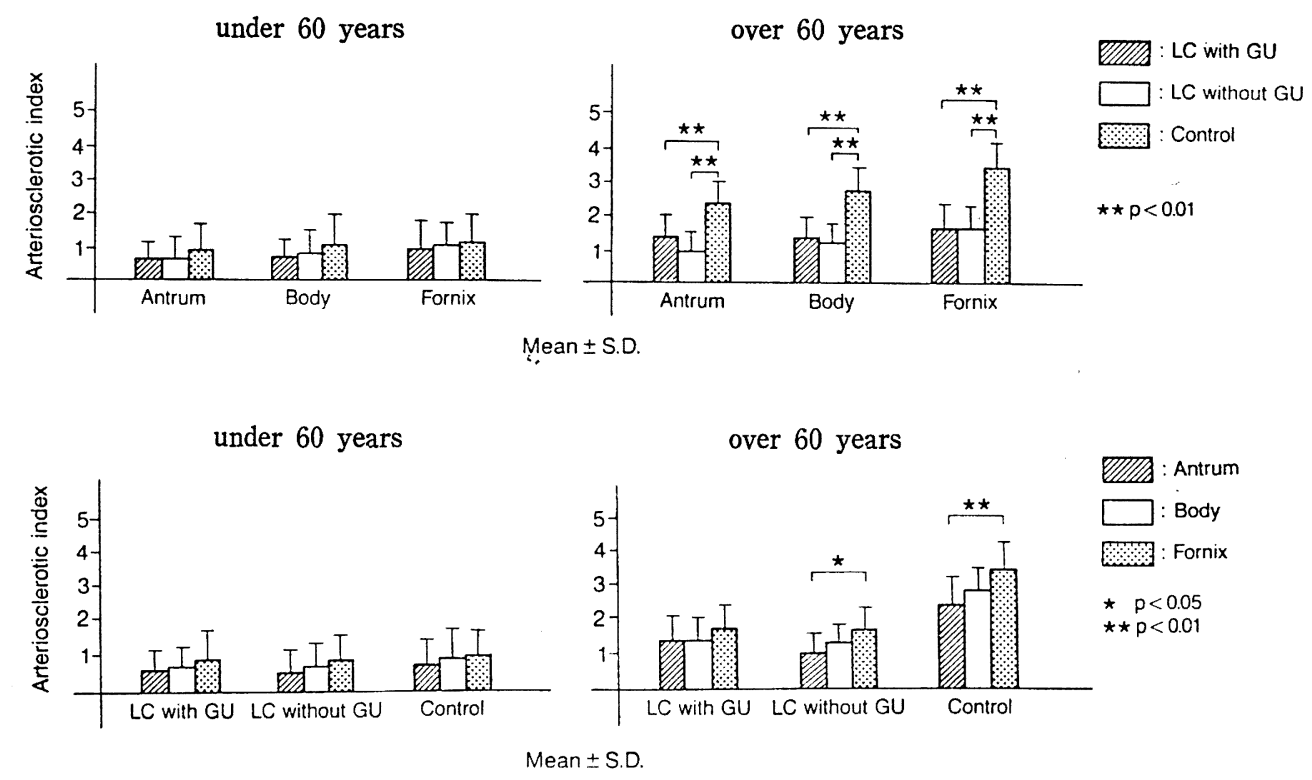

Fig. 5. Degree of arteriosclerosis at various gastric locations related to age.

LC with GU, liver cirrhosis with gastric ulcer; LC without GU, liver cirrhosis without gastric ulcer

under 60 years

over 60 years
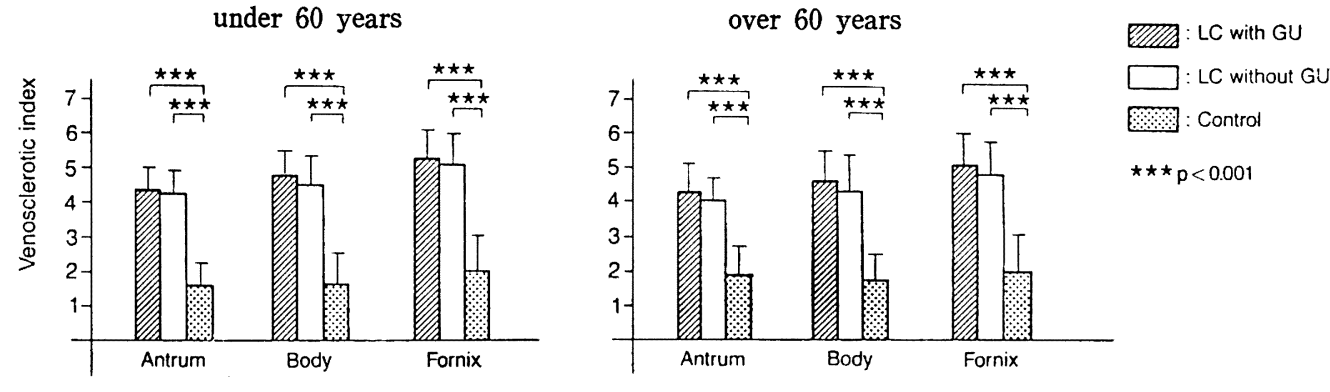

Mean \pm S.D.
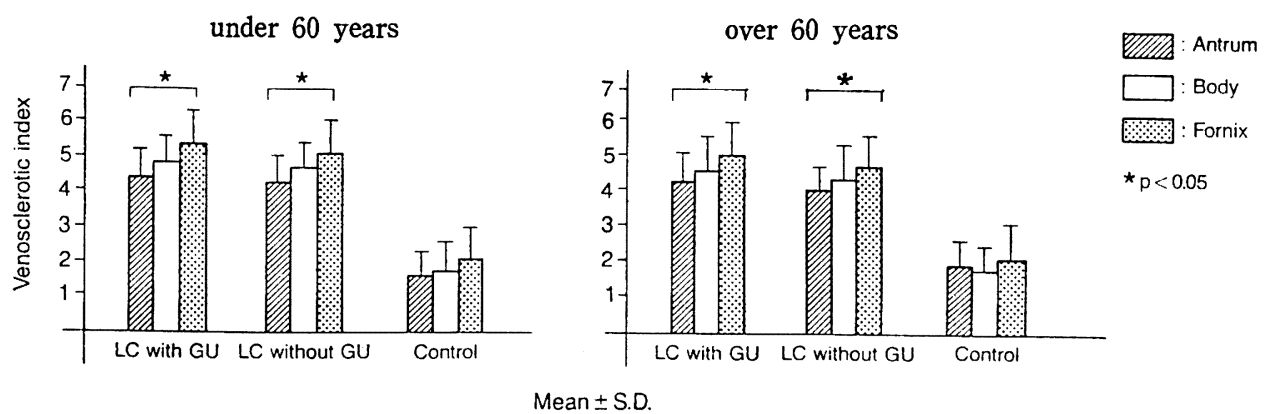

Fig. 6. Degree of venosclerosis at various gastric locations related to age. LC with GU, liver cirrhosis with gastric ulcer ; LC without GU, liver cirrhosis without gastric ulcer. 
in the fornix $(5.39 \pm 0.78)$ was significantly higher than in the antrum $(4.38 \pm 0.68)$ $(\mathrm{P}<0.05)$. In uncomplicated cirrhosis cases aged under 60 , the V.I. in the fornix $(5.12 \pm$ 0.91) was also significantly higher than in the antrum $(4.26 \pm 0.75)(P<0.05)$. In the cases aged over 60 , the index was significantly higher in the fornix $(5.01 \pm 0.91$ for $\mathrm{LC}+\mathrm{GU}$ group and $4.77 \pm 0.90$ for $\mathrm{LC}$ group) than in the antrum $(4.21 \pm 0.78$ for $\mathrm{LC}+\mathrm{GU}$ group and $4.21 \pm 0.66$ for LC group $)(P<0.05)$.

\section{Discussion}

\section{1) Ulcerogenic factors}

The association between liver cirrhosis and gastric ulcer was first investigated in this study from the aspect of ulcerogenic factors. Reports on the level of acid secretion in cirrhosis have differed widely. Some investigators have reported reduced acid secretion ${ }^{9)}$, while others have reported a slight reduction ${ }^{10)}{ }^{11}$, a slight elevation ${ }^{12)}$ or a distinct elevation ${ }^{13)}$. When acid secretion was compared between cirrhotic patients with and without gastric ulcer, those with gastric ulcer showed either a significant increase ${ }^{10) 14}$ or a tendency for an increase $^{11)}$ 15) in acid secretion. In the present study, basal acid output and maximal acid output were found to be significantly lower in cirrhotic patients both with and without gastric ulcer than in healthy controls. The absence of a significant difference in acid secretion between cirrhotic patients with and without gastric ulcer indicates that acid secretion is probably not directly involved in the onset of gastric ulcer in cirrhosis.

Many previous studies have reported a reduction of pepsin output in the gastric juice of patients with liver cirrhosis ${ }^{14)}{ }^{16)}$. Also in the present study, the basal and stimulated pepsin outputs were significantly lower in cirrhotic patients with and without gastric ulcer than in healthy controls. However, neither the basal nor the stimulated pepsin output was significantly different between the cirrhotic patients with and without gastric ulcer, suggesting that pepsin output in gastric juice is also not directly involved in gastric ulcer production in cirrhosis.

Some investigators have reported that the serum gastrin level is elevated in patients with liver cirrhosis ${ }^{13)}{ }^{17}$ ) due to impaired hepatic inactivation of gastrin. However, many other authors have disputed the idea of hepatic inactivation of gastrin ${ }^{18)}{ }^{19}$ ), and it is more widely accepted that it is broken down by the kidney ${ }^{20}$. The investigators who observed elevated blood gastrin levels in cirrhosis claimed the involvement of a feedback mechanism related to hypoacidity of the gastric juice, although others have not accepted such an idea ${ }^{9)}$. Some authors have suggested that both secretion and gastrin formation are reduced in cirrhosis to cause a fall in the serum gastrin level ${ }^{12)}$, although there is a study reporting no difference 
in serum gastrin levels between patients with cirrhosis and healthy individuals ${ }^{15)}$. In the present study, serum gastrin was found not to significantly differ between patients with cirrhosis with or without gastric ulcers and healthy controls, suggesting that the serum gastrin level was not directly involved in the development of gastric ulcers in cirrhosis.

Serum secretin levels have been reported to be high in cirrhosis in some studies ${ }^{21)}{ }^{22)}$, but no significant difference has been found between cirrhosis and healthy controls in other studies ${ }^{91}$ 11). In the present study, serum secretin levels did not significantly differ between patients with cirrhosis with or without gastric ulcers and healthy controls. Therefore, it is unlikely that serum secretin plays an important role in the development of gastric ulcer in cirrhosis. Pepsinogen I levels were reported by Adachi ${ }^{16)}$ to be significantly lower in cirrhotic patients than in healthy individuals. In the present study, cirrhotic patients with and without gastric ulcer also showed a significant reduction in serum pepsinogen I levels compared to healthy controls. However, the levels were not significantly different between cirrhotic patients with and without gastric ulcers, suggesting that changes in serum pepsinogen I levels are also unlikely to be involved in the development of gastric ulceration in cirrhosis.

\section{2) Defensive factors}

Further discussion of this issue involves the aspect of defensive factors. In the present study, I visualized the glandular border using the endoscopic Congo red test, which allows sensitive and simple assessment of the acid-secreting area and the area of atrophic mucosa. According to some investigators, the closed type is rare and the open type is frequent in cirrhosis, indicating the progression of atrophy of the fundic glands ${ }^{23}$. In the present study, the glandular border tended to be located higher in cirrhotic patients with and without gastric ulcer as compared to healthy controls and patients with gastric ulcer alone.

When the background condition of the mucosa was investigated, cirrhotic patients with and without gastric ulcer showed atrophic changes and intestinal metaplasia. This was frequently accompanied by redness. A high incidence of atrophic gastritis in cirrhosis was also found in our previous study ${ }^{1)}$. The mucosal redness of the gastric body represents congestion and is caused by marked dilatation of capillaries due to elevated portal pressure 16). These results suggest that defensive functions are reduced in the gastric mucosa in cirrhosis.

The site of gastric ulceration in cirrhosis differs from report to report. Some investigators have stated that the site is often the gastric angle ${ }^{11}$, while others have reported that it is frequently the midsection of the gastric body and sometimes the upper gastric body ${ }^{15)}$. In the present study, gastric ulcer was most frequently found in the gastric angle, and it was more frequently seen in the body than in the antrum. 


\section{3) Presence of esophageal varices}

Regarding the association between esophageal varices and gastric ulcer in cirrhosis, Fukumoto et al. ${ }^{24)}$ have reported that the incidence of gastric ulcer was higher in cirrhotic patients with varices and that the incidence increased as the varices became more severe. Matsui et al. 11) also reported that the incidence of gastric ulcer tended to increase as esophageal varices became more severe. They attributed this to regional congestion, i. e., the circulatory disturbances due to portal hypertension were seen as a major factor in the onset of gastric ulcer and acid was seen as a secondary factor which affects the weakened mucosa. In addition, Fukuda et al. ${ }^{25)}$ have reported that the portal pressuse tends to be higher in cirrhotic patients with gastric ulcer than in uncomplicated cirrhosis, and that the incidence of gastric ulcer was higher in cirrhotic patients with esophageal varices. They speculated that the mucosal lesions which occurred as esophageal varices became more severe were attributable to regional disturbances of gastric mucosal circulation due to portal hypertension. The present study also showed that the incidence of gastric ulceration tended to increase in parallel with the severity of the esophageal varices.

\section{4) Sclerosis of the blood vessels}

A pathological study of the degree of arteriosclerosis by Atari ${ }^{26)}$ showed that arteriosclerosis of the stomach was more frequent and more severe in the region of the left gastric artery than in the pyloric glandular region supplied by the right gastric artery. In the present pathological autopsy study, controls aged over 60 years had more marked arteriosclerosis in the fornix than in the antrum, supporting the reports of Kawamura ${ }^{7)}$ and $\operatorname{Atari}^{26)}$. Regarding gastric wall arteriosclerosis and cirrhosis, it has been reported that arterial lesions are remarkably mild in cirrhotic patients with gastric ulcers ${ }^{27)}$. In the present study, the degree of arteriosclerosis in the antrum, gastric body, and fornix was significantly lower in cirrhotic patients both with and without gastric ulcers aged over 60 years than in controls of the same age group $(P<0.01)$, although no significant difference was noted at ages below 60 years. Regarding venosclerosis, Shizawa et al, ${ }^{28)}$ performed a histological study of stomachs removed from cirrhotic patients with gastric ulcers, and found that dilatation of the gastric wall veins and hypertrophy of the intima were already marked in the early stages of cirrhosis. This suggested the involvement of disturbed gastric mucosal circulation in ulceration even from the early stages of cirrhosis. Watanabe ${ }^{29}$ ) has attributed the onset of mucosal lesions to the weakening of mucosal defensive functions by disturbances of the gastric mucosal circulation (venous congestion). Such changes are gradually caused by the development of gastric mucosal venosclerosis following congestion in the portal region due to portal hypertension. Venous lesions of the gastric wall in cirrhosis are claimed to be more 
severe in patients with gastric ulcers than in those without them ${ }^{27)}$. In the present study, the degree of venosclerosis was significantly higher in cirrhotic patients both with and without gastric ulcers than in controls. However, because it did not significantly differ between cirrhotic patients with and without gastric ulcers, it seems impossible to explain the development of gastric ulceration based on venosclerosis alone.

In the past, the onset of gastric ulcer in cirrhosis has been studied mainly from the aspect of gastric mucosal blood flow, but no previous study has assessed the degree of gastric mucosal arteriosclerosis and venosclerosis in determining the role of gastric mucosal blood flow in the onset of gastric ulceration. Particular attention was paid to this point in designing the present study.

\section{5) Proposed mechanism of induction of gastric ulceration in liver cirrhosis}

The results of the present study suggested the following mechanism for the development of gastric lesions in liver cirrhosis. First, venous dilatation of the gastric wall and hypertrophy of the intima occur due to portal hypertention, and are followed by worsening of gastric wall venosclerosis. As a result, congestion and circulatory disturbances occur, thatlead to weakening of the mucosa, i. e., a reduction of its defensive functions. Accordingly, the balance between ulcerogenic and defensive factors is lost, and this leads to the development of gastric lesions.

\section{Summary}

The mechanism of the complication of liver cirrhosis by gastric ulcer was studied from various aspects, including the kinetics of gastric juice secretion, gastrointestinal hormones, fasting serum pepsinogen I, the condition of the gastric mucosa, the site of gastric ulceration, and the presence of esophageal varices. In addition, it was histopathologically studied by examining arterioscleosis and venosclerosis of the gastric wall in autopsy cases. Both the basal and stimulated acid and pepsin outputs were significantly lower in cirrhotic patients with and without gastric ulcers than in healthy controls $(\mathrm{P}<0.01)$. Fasting serum gastrin and secretin did not significantly differ between cirrhotic patients and healthy controls. Fasting serum pepsinogen I in cirrhotic patients was significantly lower than in healthy controls $(\mathrm{P}<0.05)$. The level of the glandular border in cirrhotic patients tended to be higher than in healthy controls and the gastric ulcers at all age groups. Endoscopic observation of the mucosa showed that normal mucosa was uncommon in cirrhotic patients both with and without gastric ulcers. In these patients, atrophic changes and erythema were frequent. Both gastric ulcer patients and cirrhotic patients with gastric ulcers frequently had ulcers in the gastric angle and lesser curvature at all ages. The incidence and severity of esophageal varices tended to be higher in cirrhotic patients with gastric 
ulcers than in those without gastric ulcers. The red color sign was positive in many of the cases complicated by gastric ulcer. The degree of arteriosclerosis in the antrum, gastric body, and fornix was significantly lower in cirrhotic patients both with and without gastric ulcers aged over 60 years than in controls of the same age group $(P<0.01)$. The degree of venosclerosis of the antrum, gastric body and fornix was significantly higher in cirrhotic patients both with and without gastric ulcers than in controls aged under and over 60 $(P<0.001)$. In cirrhotic patients with and without gastric ulcer aged under and over 60, the venosclerotic index in the fornix was significantly higher than in the antrum $(P<0.05)$.

The results of the present study suggested that venous congestion and circulatory disturbances occur by gastric wall venosclerosis due to portal hypertension, and lead to weakening of the mucosa, i.e., a reduction of its defensive functions. Accordingly, the balance between ulcerogenic and defensive factors is lost, and this leads to the development of gastric lesions.

\section{Acknowledgements}

This investigation was made possible through the cooperation with The Third Department of Internal Medicine directed by Prof. Yoshiko Sameshima to whom I am greatly indebted. I am grateful to Drs. Takako Mizuno and Jiro Tateiwa for their helpful cooperation.

\section{References}

1) Tsuruta, I., Tateiwa, J., Hiramatsu, A., Sasakawa, M., Mizuno, T. and Sameshima, Y. : Peptic ulcer in patients with liver disease. J. Kansai Med. Univ., 33, 380 388, 1981.

2) The report of the ninth Gastric Juice Assay Committe. : Jpn. J.Gastroenterol, 69, 8, 1972.

3 ) The report of the eleventh Gastric Juice Assay Committee. : Jpn. J.Gastroenterol, 70, 172 173, 1973.

4) Miki, K., Chang, C.M., Ichinose, M., Niwa, H. and Oka, H. : Relationship between the endoscopic type of the glandular border by congo red test and the serum pepsinogen levels by radioimmunoassay, and the gastric acid-pepsin analysis. Gatroenterol. Endosc., 25, 1920 1926, 1983.

5 ) Iida, Y., Nakamura, K., Kawamura, S., Okazaki, Y., Sakaki, N. and Takemoto, T. : Difference between endoscopic and histological atrophic border in chronic gastritis. Gastroenterol. Endosc., 19, 551 554, 1977.

$6)$ The report of Portal Surgery Research. : The criteria of endoscopic esophageal varix. A proposed staging method by some factors. Acta Hepatologica Japonica, 17, 566 568, 1976.

7 ) Kawamura, S., Aoyama, S., Iida, Y., Hamada, Y., Fuji, T., Shimizu, M., Odawara, M., Sakaki, N., Hirata, M., Watanabe, M., Ariyama, S., Azuma, M., Kawahara, K., Fujita, K., Maetani, N., Morita, M., Okazaki, Y., Nakamura, K. and Takemoto, T. : A study on the relation between arteriosclerosis and gastric lesions. Jpn. J.Gastroenterol, 75, 639 649, 1978.

8 ) Arai, I. : Pathological study on phlebosclerosis. The Kitakanto Med. J., 18, 596 620, 1968.

9) Iizuka, Y., Azima, H., Kondou, Y., Suzuki, S., Kaneko, R., Niizuma, K., Hamada, A., Saji, K., Nakai, M. and Tachibana, F. : A study on Etiopathogenesis of peptic ulcer in liver cirrhosis. Fukushima Med. J., 34, 323 333, 1984. 
10) Urabe, K. : Studies on gastric acid and pepsin secretion in liver cirrhosis. Jpn. J.Gastroenterol, 77, 750 757, 1980.

11) Matsui, S., Urakawa, T., Nagahata, Y., Hayashi, T., Hirai, Y., Nakamoto, M., Fukuoka, S., Kumagai, K., Nakayama, Y., Kagawa, S., Takata, T., .Takase, N. and Saitoh, Y. : Clinical studies on the gastro-duodenal lesions in liver cirrhosis-Especially in the view of gastric acid secretion-. Jpn. J. Gastroenterol. Surg. , 18. 2017 2025, 1985.

12) Hidaka, T. : A study of mechanism of gastric ulcer formation in liver cirrhosis. Hiroshima Med. J., 29, 1189 1206, 1981.

13) Lauristen, K. B., Rehfeld, J. F., Chritiansen, L. A., Juhl, E. and Stadil, F. : Serum-gastrin in cirrhosis. Scand. J.Gastroenterol, 37, 33 34, 1976.

14) Sakaue, H. and Mizukami, Y. : Studies on the etiology of gastric ulcers or erosions in patients with liver cirrhosis. Gastrenterol. Endosc, 28, 1143 1146, 1986.

15) Sato, Y. : Clinical and experimental studies on peptic ulcers complicating liver diseases. J. Nihon Univ. Med. Ass., , 45, 115 125, 1986.

16) Adachi, H. : The study of gastric mucosal changes and it's mechanism in patients with liver cirrhosis. Gastroenterol. Endosc., 29, 455 471, 1987.

17) Masuoka, T., Mitsumoto, S., Kiryu, T., Satoh, S. and Abe, M. : Radioiommunoassay of serum gastrin. Med. Postgraduates, 11, 238 245, 1973.

18) Denker, H., Hakanson, R., Liedberg, G., Norryd, C., Oscarson, J., Rehfeld, J. F. and Stadil, F. : Gastrin in portal and peripheral venous blood after feeding in man. Gut., 14, 856 860, 1973.

19) Pointer, H. : Normal serum gastrin levels in patients with liver cirrhosis. Digestion, 13, 372 374, 1975.

20) Reeder, D. D., Brande, E. N. Jr, Watoson, L.C., Hjelmquist, U. B. E. and Thompson, J. C. : Preand post hepatic measurements of mass of endogenous gastrin. Surg., 72, 34 41, 1972.

21) Yamaguchi, T., Abe, K., Zeze, F. and Yanaihara, N. : Radioimmunoassay of secretin. J. Therap., 58, 1513 1520, 1976.

22) Chey, W. Y., Hendricks, J., Lober, S. H. : Inactivation of secretin by the liver. Clin. Res., 19, 389 393, 1971.

23) Sakaue, H. and Ohta, Y. : Gastroenterological diseease in liver cirrhosis-mechanism of disease and therapy-. Jpn. J.Clin. Med., 46, 1052 1058, 1988.

24) Fukumoto, Y., Maetani, N., Nagatomi, Y., Numa, Y., Andou, K., Tsubota, W., Saito, M., Oda, M., Esaki, T., Takeuchi, K., Ogino, M., Hiro, K., Hanta, T., Konishi, T., Iida, Y., Kodama, T., Okita, K., Okazaki, Y. and Takemoto, T. : Studies of gastro-mucosal changes in patients with chronic liver diseases. Yamaguchi Med. J., 31, 491 499, 1982.

25) Fukuda, M., Kawano, S., Sato, N., Shimazu, R., Nagano, K., Tsuji, S., Fusamoto, H. and Kamada, T. : Gastric mucosal hemodynamics and oxygen sufficiency in patients with liver cirrhosis assessed by reflectance spectrophotometry. Jpn. J. Gastroenterol., 83, 26〜32, 1986.

26) Atari, H. : A study on the vascular change of gastrointestinal tract. - especially on normal vascular structure and its aging-. Gastroenterol. Endosc., 21, 620 621, 1979.

27) Namatame, K. : A pathological studies on the complication of gastric peptic ulcer in cirrhosis of the liver. J. Showa Med. Assoc., 36, 253 262, 1976.

28) Shizawa, Y., Kohno, M., Kasai, N., Koike, Y., Mizuguchi, A., Fujii, M., Iwabuchi S., Nakagome, T., Watanabe, Y., Okabe, K., Uchikoshi, T. and Sekizawa, H. : Clinical studies on peptic ulcer in patients with liver cirrhosis. Progress of Digestive Endoscopy, 28, 127 130, 1986.

29) Watanabe, T. : A study of the gastric mucosal change in the liver damage. Jpn. J. Gastroenterol., 84, 2649 2657, 1987. 